\section{A fresh start for International Journal of Medical and Surgical Sciences, a new standard.}

\section{Ricardo Cartes-Velásquez ${ }^{1}$}

As I hope you have already noted, the first issue of the International Journal of Medical and Surgical Sciences has been delayed this year. The delay is not due to a lack of articles or problems in the editorial process but because of a series of changes implemented to improve the overall quality of the journal.

Over the past four years, the International Journal of Medical and Surgical Sciences has implemented almost no changes to its editorial process, production process, or divulgation channel (its website). The lack of changes could be good, bad, or neutral, depending on the standards you use to evaluate the journal. No matter which standards you use, however, the big truth is that standards are not final standards.

I cannot find or imagine any field in which the standards have not evolved over the past two decades or, in some cases, over the past two years or even a shorter time span. To clarify, when I say field, I mean scientific fields, and knowledge dissemination is a scientific field named scientometrics or bibliometrics.

In bibliometrics, many changes have occurred since the time of just counting citations. Over the past few years, bibliometrics has expanded its scope to include other kinds of data linked to the advancement of scientific knowledge. We can say that bibliometrics has changed its measurement standards.

But some things have not changed in bibliometrics; scientific journals still dominate the market of channels disseminating new knowledge. There are some exceptions in the humanities and related fields, but overall, scientific journals are "the way" to communicate new knowledge in the scientific arena.

However, journals have changed; they have evolved. This fact probably explains why scientific journals still dominate as "the way" to share knowledge. The evolution of scientific journals includes not only digitalization (scanning and publishing PDFs on the Internet), but the inclusion of new data and services to facilitate the work for readers, bibliometricians, and even for science policymakers. So, new standards have emerged to regulate which data must to be included and how it must be presented.

Thus, the question arises, was the International Journal of Medical and Surgical Sciences complying with the new standards for
INT J MED

SURG SCI

Affiliations: ${ }^{1}$ Universidad Autónoma de Chile, Chile.

\section{Corresponding author: Ricardo}

Cartes-Velásquez. Beltrán Mathieu 7, Concepción. Phone: 56-977575655.

E-mail: ijmss@uautonoma.cl

Conflict of interests: None.

Acknowledgements: None.

doi: $10.32457 /$ ijmss.2018.001. 
scientific journals? The answer is "partially," so you can see the glass as half full or half empty. Our vision is to keep an iterative process of improvement for the International Journal of Medical and Surgical Sciences. Thus, for us, the glass is half empty.

In this regard, we have implemented a set of three changes. First, we left the old website powered by WordPress for one that is run through an Open Journal System website. This is not just an aesthetic change but a change in the way readers and databases access the journal content. The Open Journal System complies with major standards in this matter, so the content not only will be freely accessible but easily accessible. Another relevant gain derived from using the Open Journal System is the inclusion of a structured set of data for each article, each issue, and the journal itself.

Second, all articles of the journal now will have a DOI number. You probably already know about DOI numbers and the advantage they provide in getting an article without needing to access a particular database or website; you just enter the DOI in your Internet browser and you get the correct URL for the full text (CartesVelásquez, 2015).

Third, we have changed the layout of the journal. As with the website, this is not just an aesthetic change but a content change. Now you have access to relevant data for each article, including dates of receipt, revision, acceptance, online availability, conflict of interest, ethics approval, funding, authors' contributions, and acknowledgements. In the aesthetic aspect, we are trying a layout focused highlighting each article's relevant data and providing space to take notes on print or electronic versions.

With these changes, is the International Journal of Medical and Surgical Sciences now complying with the new standards for scientific journals? The answer is yes. Is the journal complying with the new standards for scientific journals to come over the next few years? The answer is no. The strategy is to keep evolving and complying with changing standards to offer you a quality journal for communication in the medical and surgical sciences worldwide.

As a final comment, please feel free to send us commentaries, criticisms, suggestions, or questions so we can continue to improve the quality of the International Journal of Medical and Surgical Sciences.

\section{REFERENCES}

Cartes-Velasquez R. Numbers and changes. J Oral Res. $2015 ; 4(1): 4-5$. 